\title{
Supplementary Materials of
}

\section{Parameterized reactivity of hydroxy radical, ozone, nitrate radical and atmospheric oxidation capacity during summer at a suburban site between Beijing and Tianjin}

Yuan Yang ${ }^{1,2}$, Yonghong Wang ${ }^{3}$, Dan Yao ${ }^{1,2,6}$, Dongsheng Ji ${ }^{1}$, Jie Sun ${ }^{1}$, Yinghong Wang ${ }^{1}$, Shuman

Zhao $^{1,2}$, Wei Huang ${ }^{1,2}$, Shuanghong Yang ${ }^{1,5}$, Wenkang Gao ${ }^{1}$, Zirui Liu ${ }^{1}$, Bo Hu${ }^{1}$, Renjian Zhang ${ }^{1}$, Limin Zeng ${ }^{4}$, Tuukka Petäjä3 ${ }^{3}$, Veli-Matti Kerminen³, Markku Kulmala ${ }^{3}$, Yuesi Wang ${ }^{1,2,6}$

${ }^{1}$ Institute of Atmospheric Physics, Chinese Academy of Sciences, Beijing 100029, China

${ }^{2}$ University of the Chinese Academy of Sciences, Beijing 100049, China

${ }^{3}$ Institute for Atmospheric and Earth System Research / Physics, Faculty of Science, P.O.Box 64, 00014 University of Helsinki, Helsinki, Finland

${ }^{4}$ State Joint Key Laboratory of Environmental Simulation and Pollution Control, College of Environmental Sciences and Engineering, Peking University, Beijing 100871, China

${ }^{5}$ Department of Environmental Science and Engineering, Beijing University of Chemical Technology, Beijing 10029, China

${ }^{6}$ Center for Excellence in Regional Atmospheric Environment, Institute of Urban Environment, Chinese Academy of Sciences, Xiamen 361021, China

Submitted to Atmospheric Chemistry and Physics Corresponding to: Yonghong Wang, yonghong.wang@helsinki.fi; Yuesi Wang,wys@mail.iap.ac.cn 


\section{Figure captions}

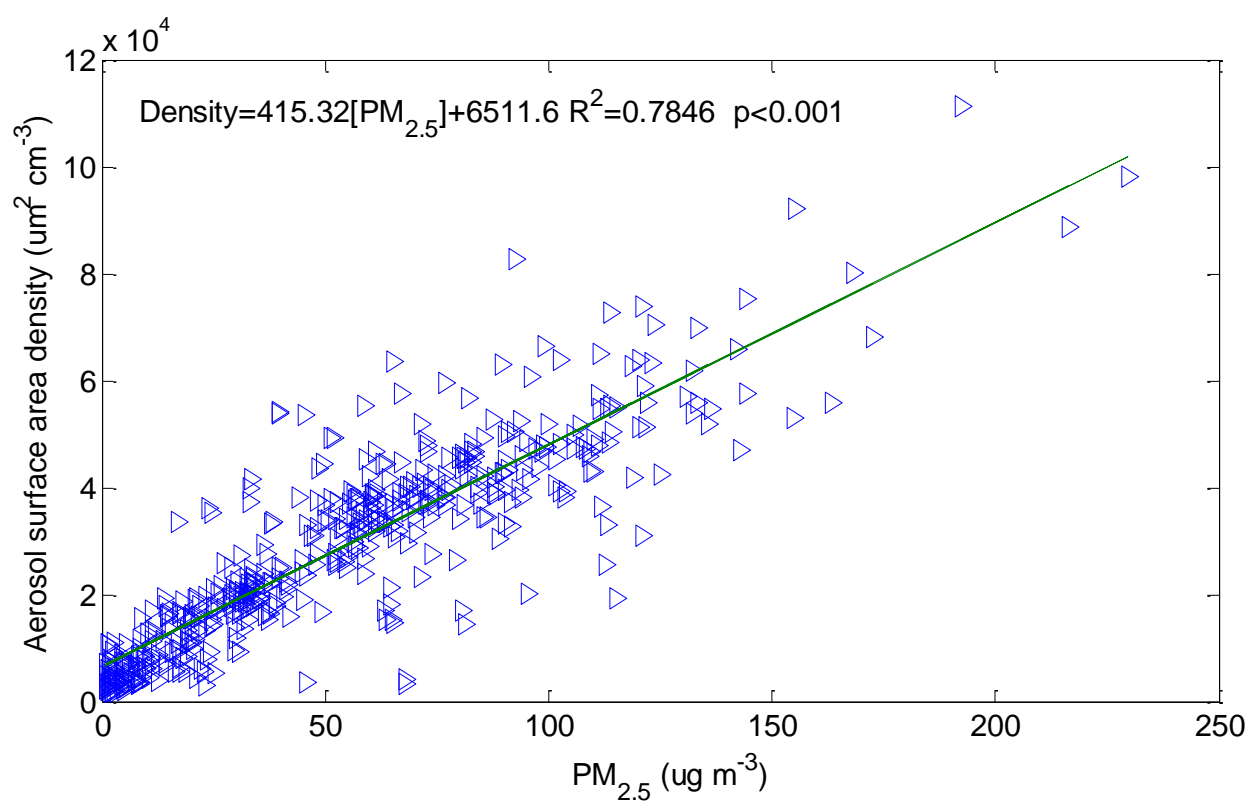

Figure S1. Correlations between aerosol surface area density and $\mathrm{PM}_{2.5}$ measured from 1 to 22 November 2018. The green solid line is the regression line.

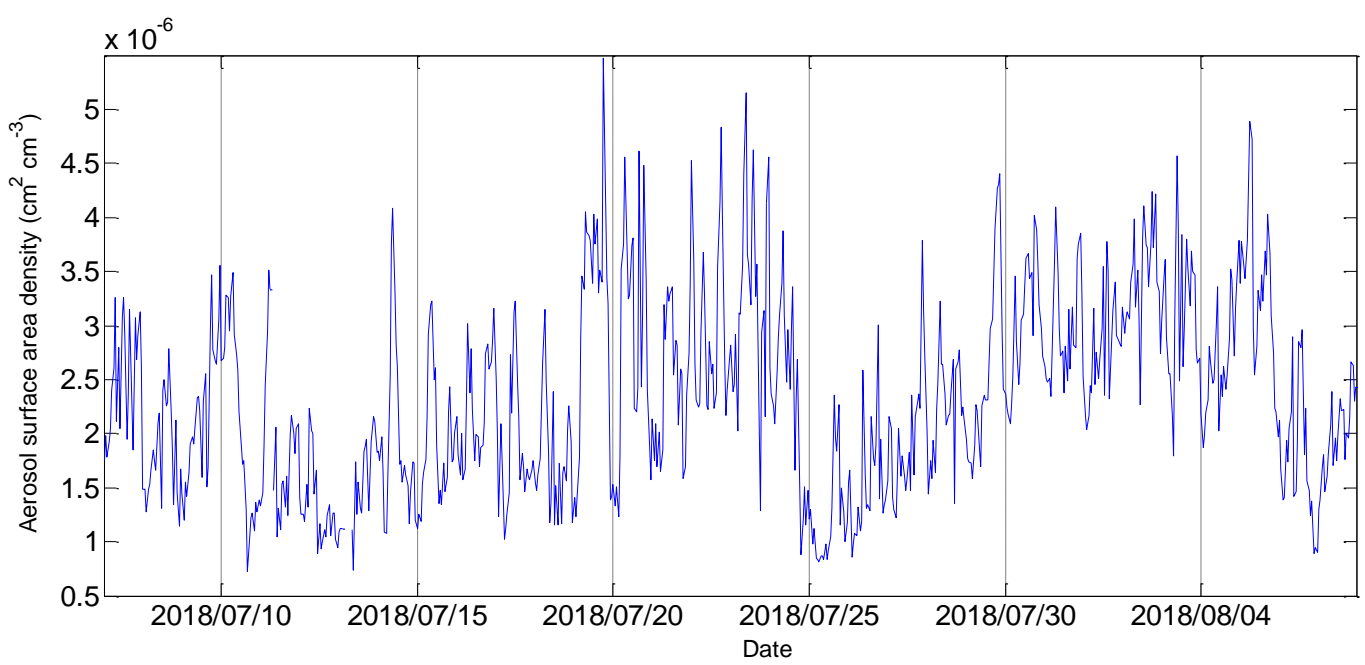

Figure S2. Time series of calculated aerosol surface area density $\left(\mathrm{cm}^{2} \mathrm{~cm}^{-3}\right)$ at a suburban site of Xianghe. 

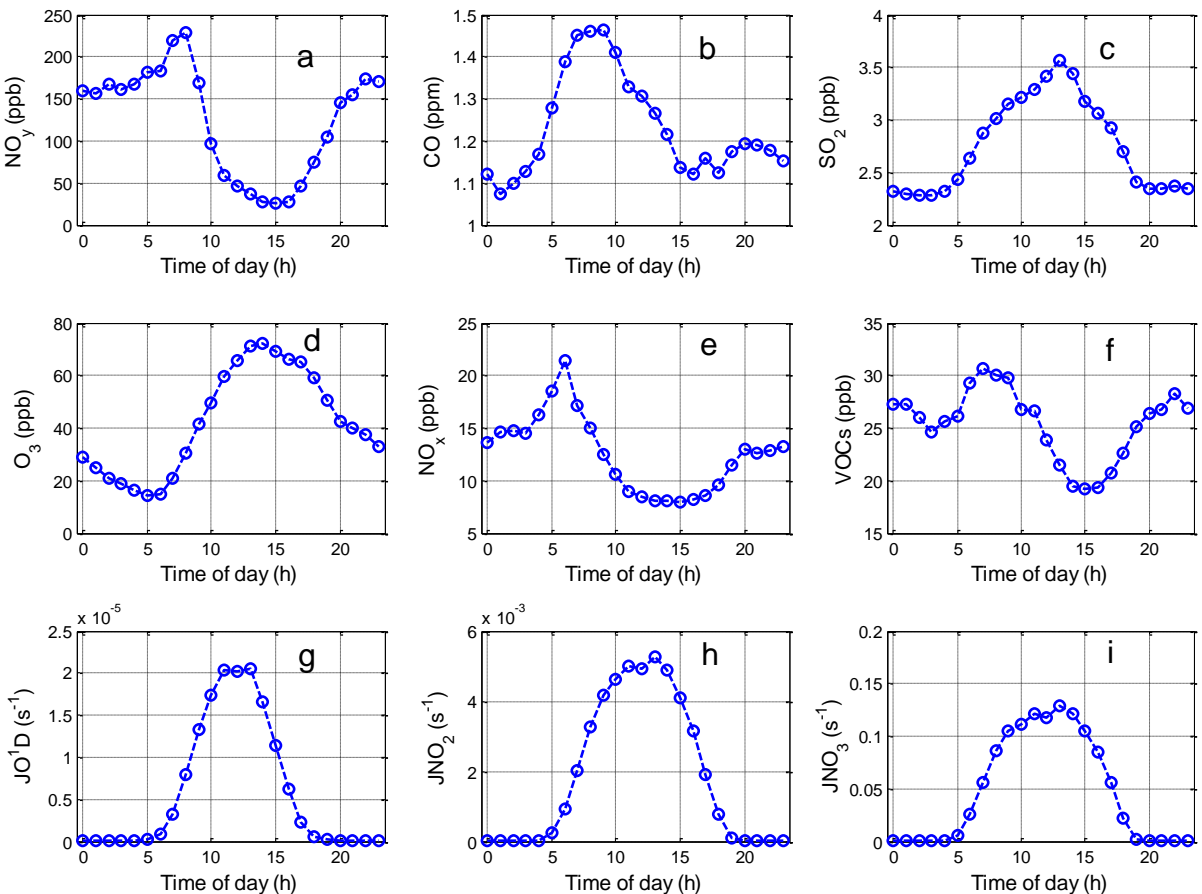

Figure S3. Mean diurnal variations of air pollutants and meteorological parameters observed during the field campaign at Xianghe from 6 July to 6 August 2018. 

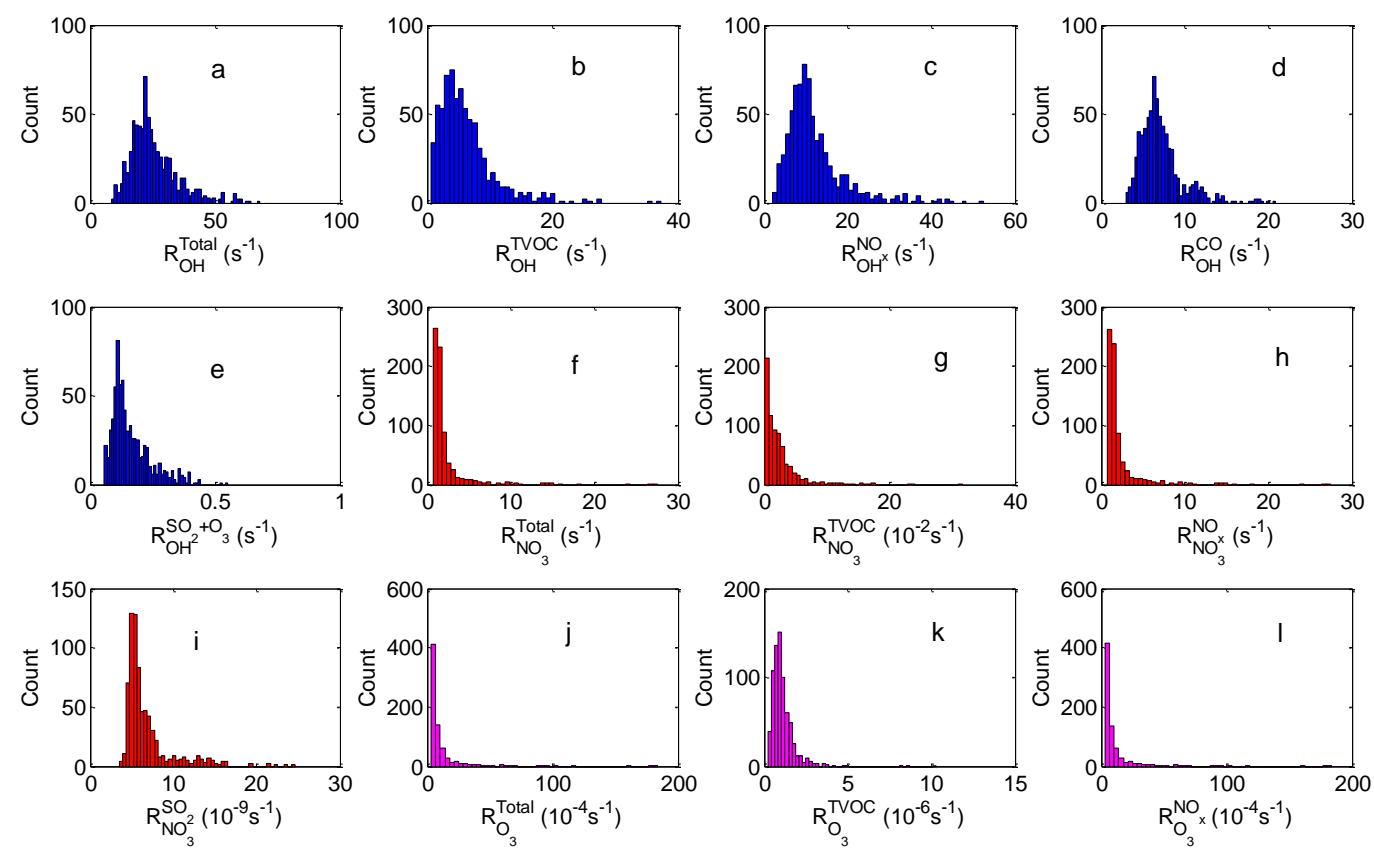

Figure S4. Frequency distributions of $R_{O H}^{\text {calculated }}, R_{\mathrm{NO}_{3}}^{\text {calculated }}$ and $R_{O_{3}}^{\text {calculated }}$ of trace gases during the field campaign at Xianghe from 6 July to 6 August 2018 . 

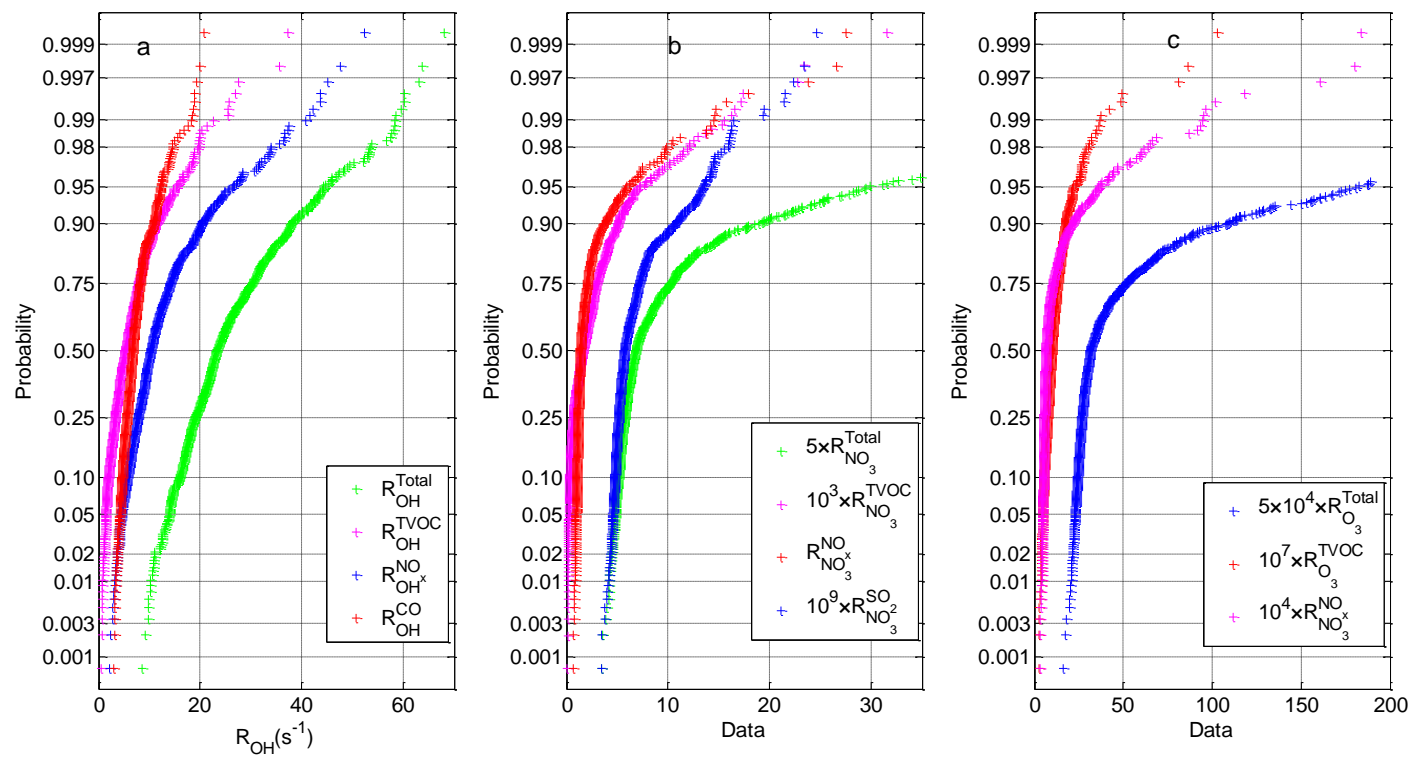

Figure S5. Cumulative frequency distributions of $R_{\mathrm{OH}}^{\text {calculated }}, R_{\mathrm{NO}_{3}}^{\text {calculated }}$ and $R_{\mathrm{O}_{3}}^{\text {calculated }}$ of trace gases during the field campaign at Xianghe from 6 July to 6 August 2018. 

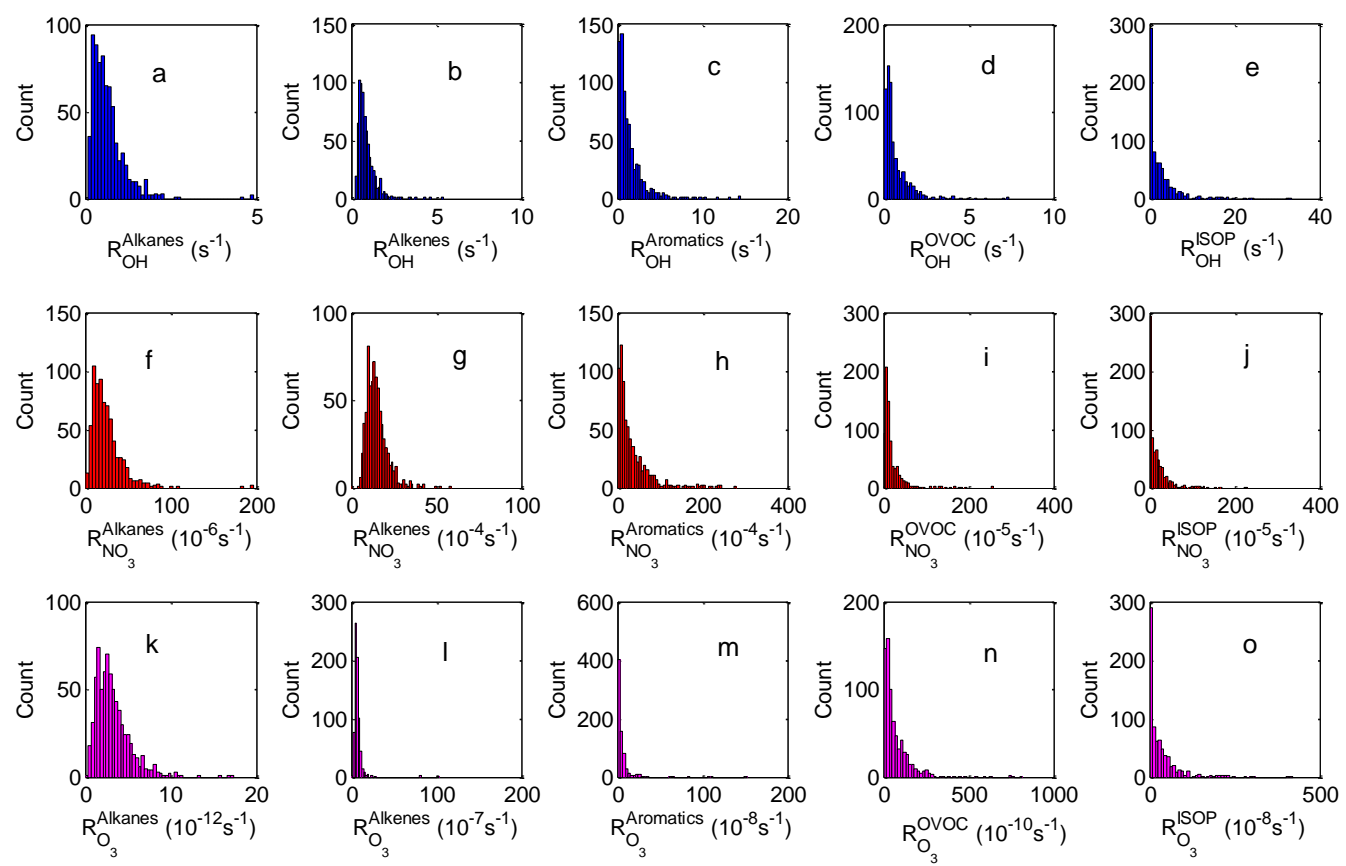

Figure S6. Frequency distributions of $R_{\mathrm{OH}}^{\text {calculated }}, R_{\mathrm{NO}_{3}}^{\text {calculated }}$ and $R_{\mathrm{O}_{3}}^{\text {calculated }}$ of VOC groups during the field campaign at Xianghe from 6 July to 6 August 2018 . 


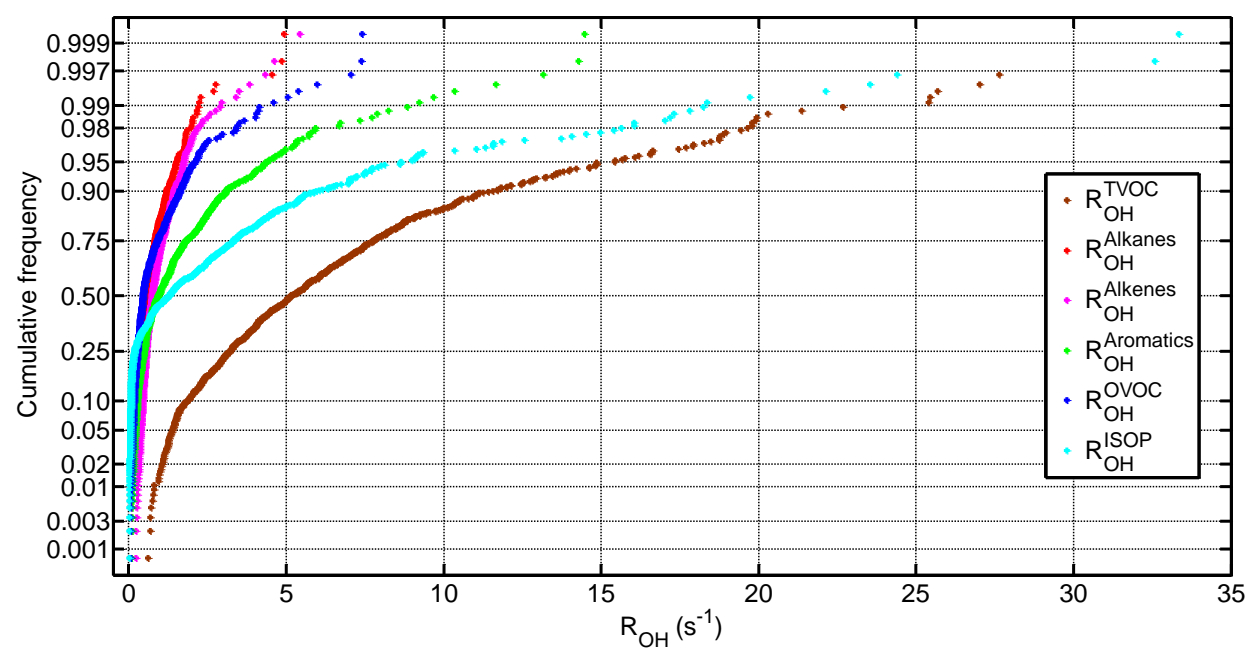

Figure S7. Cumulative frequency distributions of $R_{O H}^{\text {calculated }}$ of VOC groups during the field campaign at Xianghe from 6 July to 6 August 2018 . 


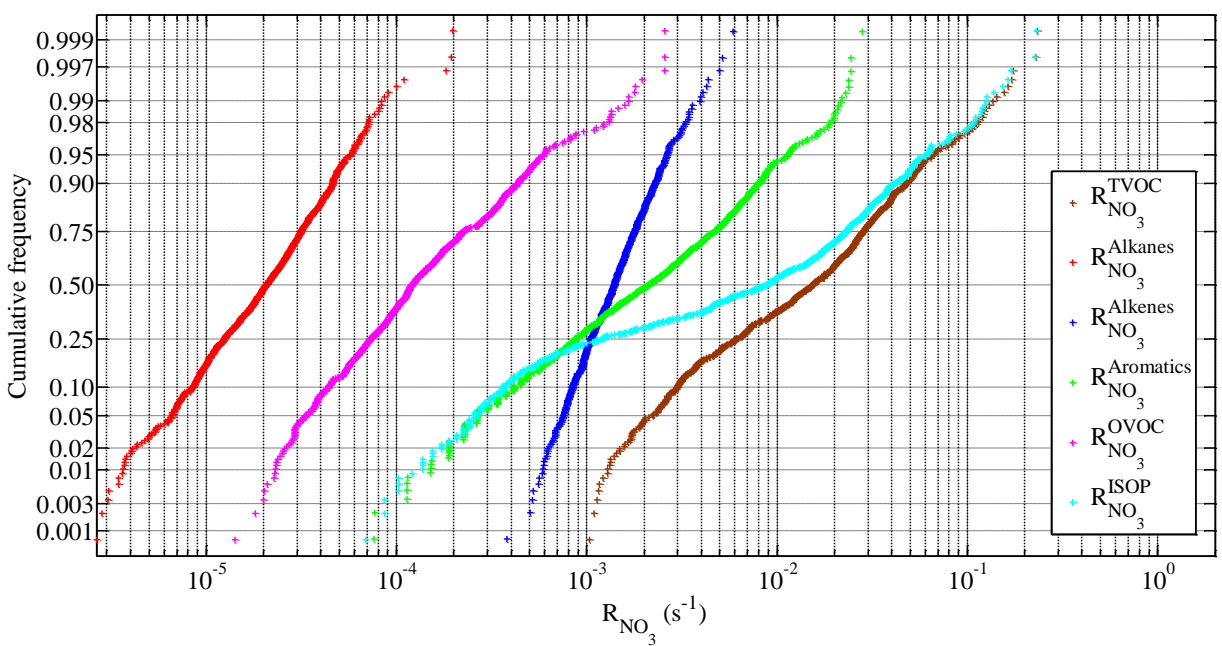

Figure S8. Cumulative frequency distributions of $R_{\mathrm{NO}_{3}}^{\text {calculated }}$ of VOC groups during the field campaign at Xianghe from 6 July to 6 August 2018. 


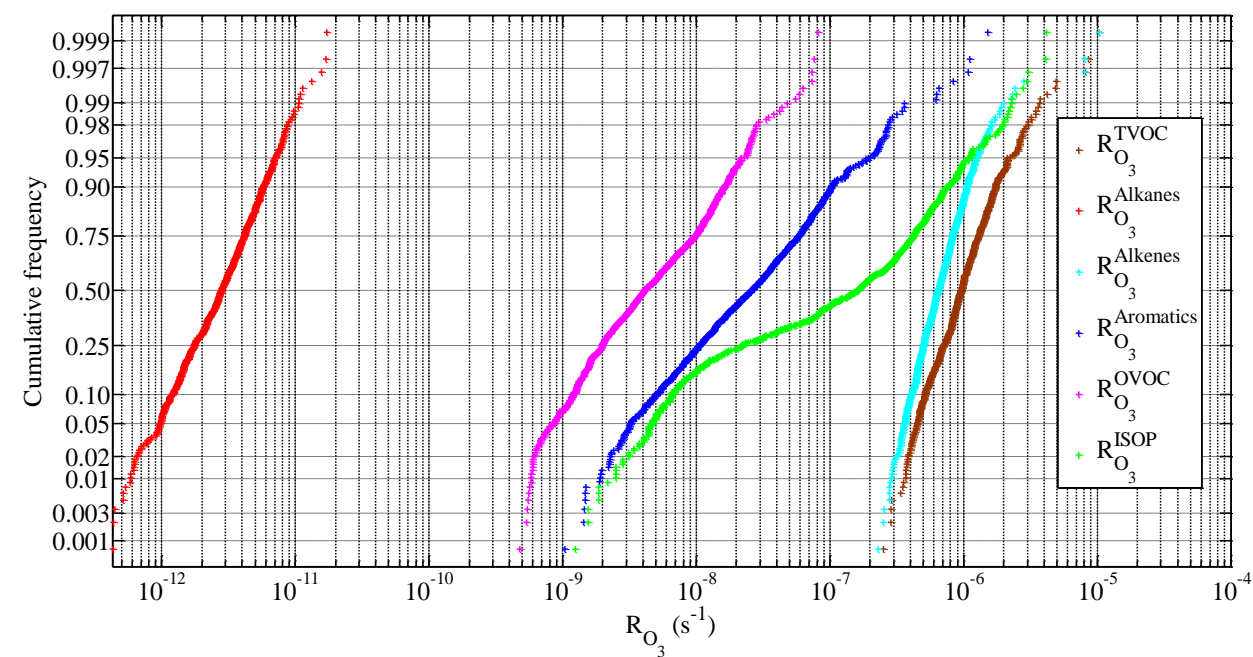

Figure S9. Cumulative frequency distributions of $R_{O_{3}}^{\text {calculated }}$ of VOC groups during the field campaign at Xianghe from 6 July to 6 August 2018. 


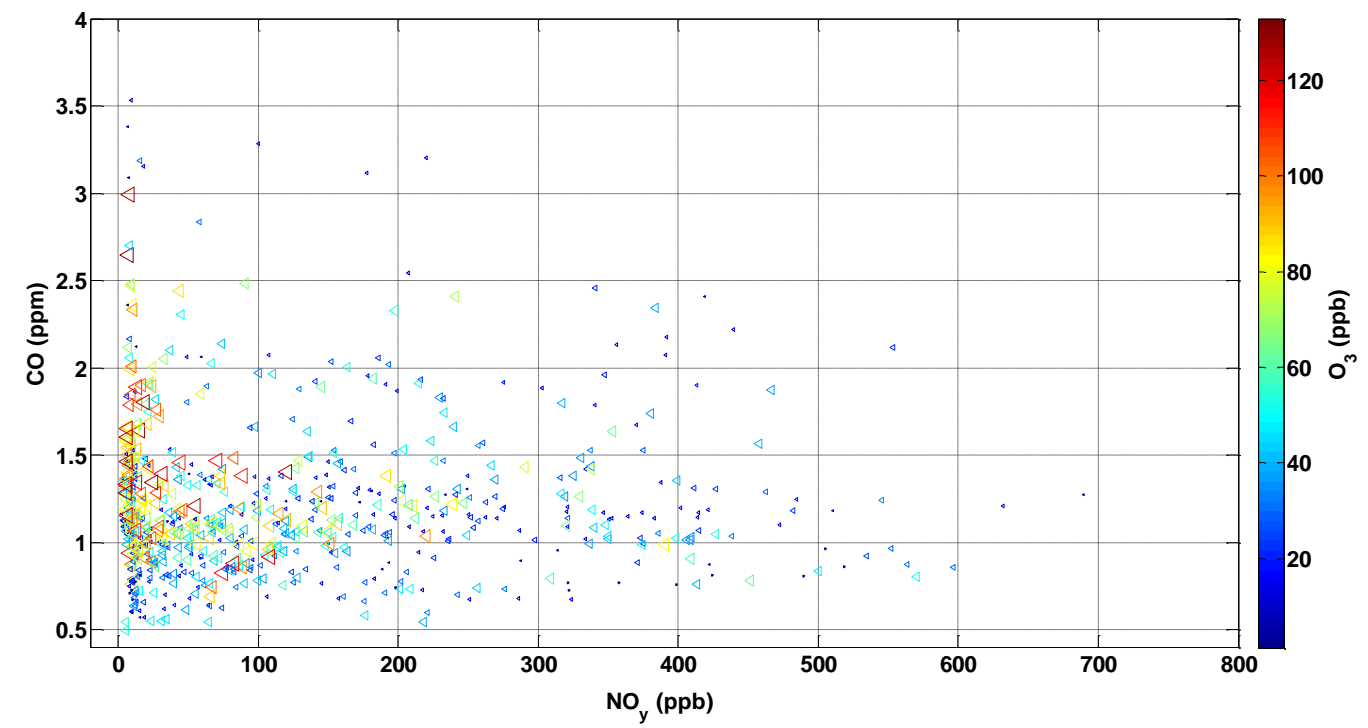

Figure S10. Scatter plots of $\mathrm{CO}-\mathrm{NO}_{\mathrm{y}}$ color-coded with $\mathrm{O}_{3}$ concentrations. It shows that high $\mathrm{O}_{3}$ levels are generally associated with air masses of high $\mathrm{CO} / \mathrm{NO}_{\mathrm{y}}$ ratio. As VOCs generally have good correlations with $\mathrm{CO}$ and play a similar role as $\mathrm{CO}$ in photochemical ozone production, the $\mathrm{O}_{3}-\mathrm{CO}-\mathrm{NO}_{\mathrm{y}}$ relationship strongly indicates a VOC-limited regime of $\mathrm{O}_{3}$ formation in Xianghe. 

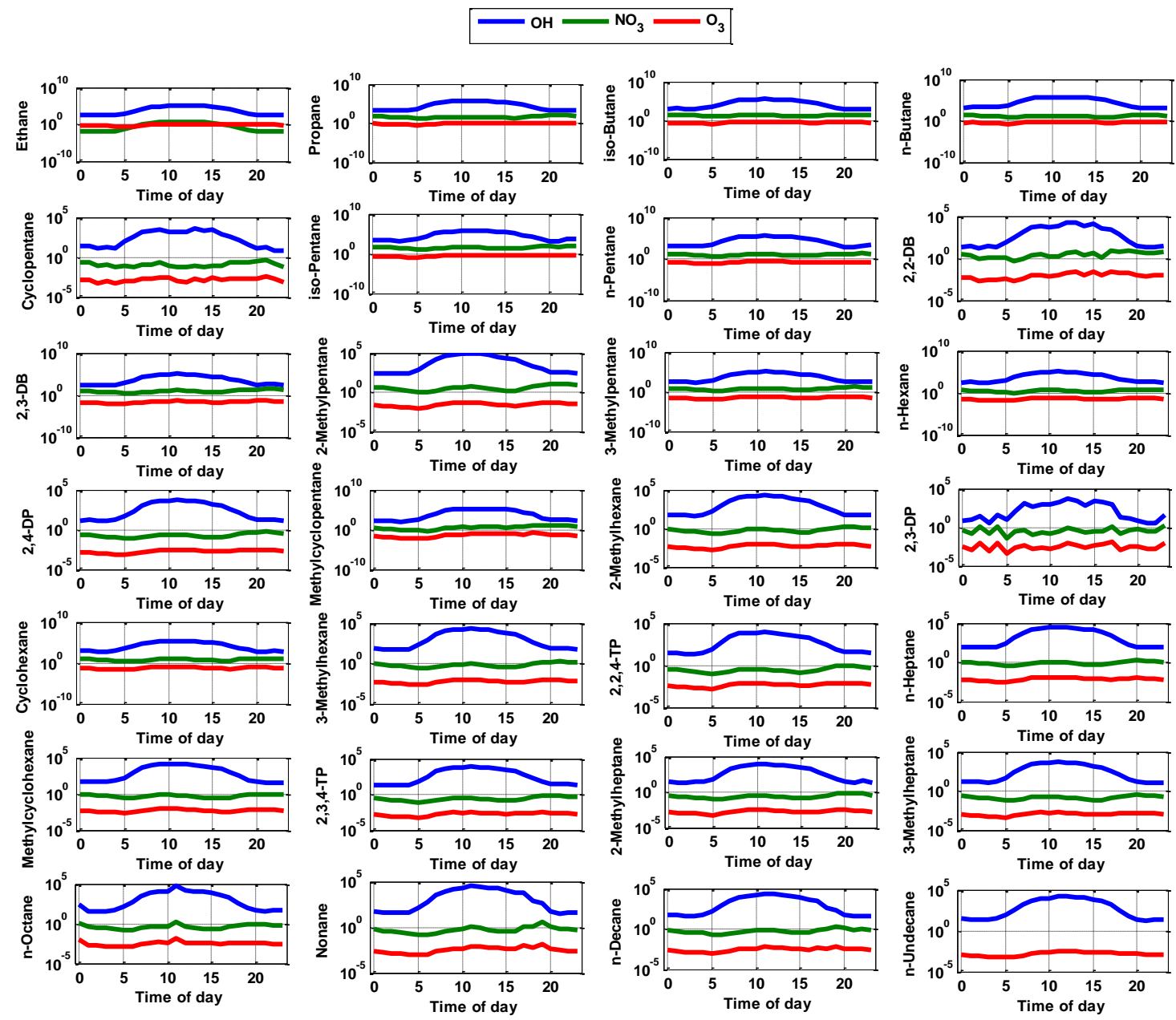

Figure S11. Diurnal variations of alkane species due to the reactions with $\mathrm{OH}$ radical (blue lines),

$\mathrm{NO}_{3}$ radical (green lines) and $\mathrm{O}_{3}$ (red lines) (unit: molecules $\mathrm{cm}^{-3} \mathrm{~s}^{-1}$ ). 2,2-DB:

2,2-Dimethylbutane; 2,3-DB: 2,3-Dimethylbutane; 2,4-DP: 2,4-Dimethylpentane; 2,3-DP:

2,3-Dimethylpentane; 2,2,4-TP: 2,2,4-Trimethylpentane; 2,3,4-TP: 2,3,4-Trimethylpentane. 

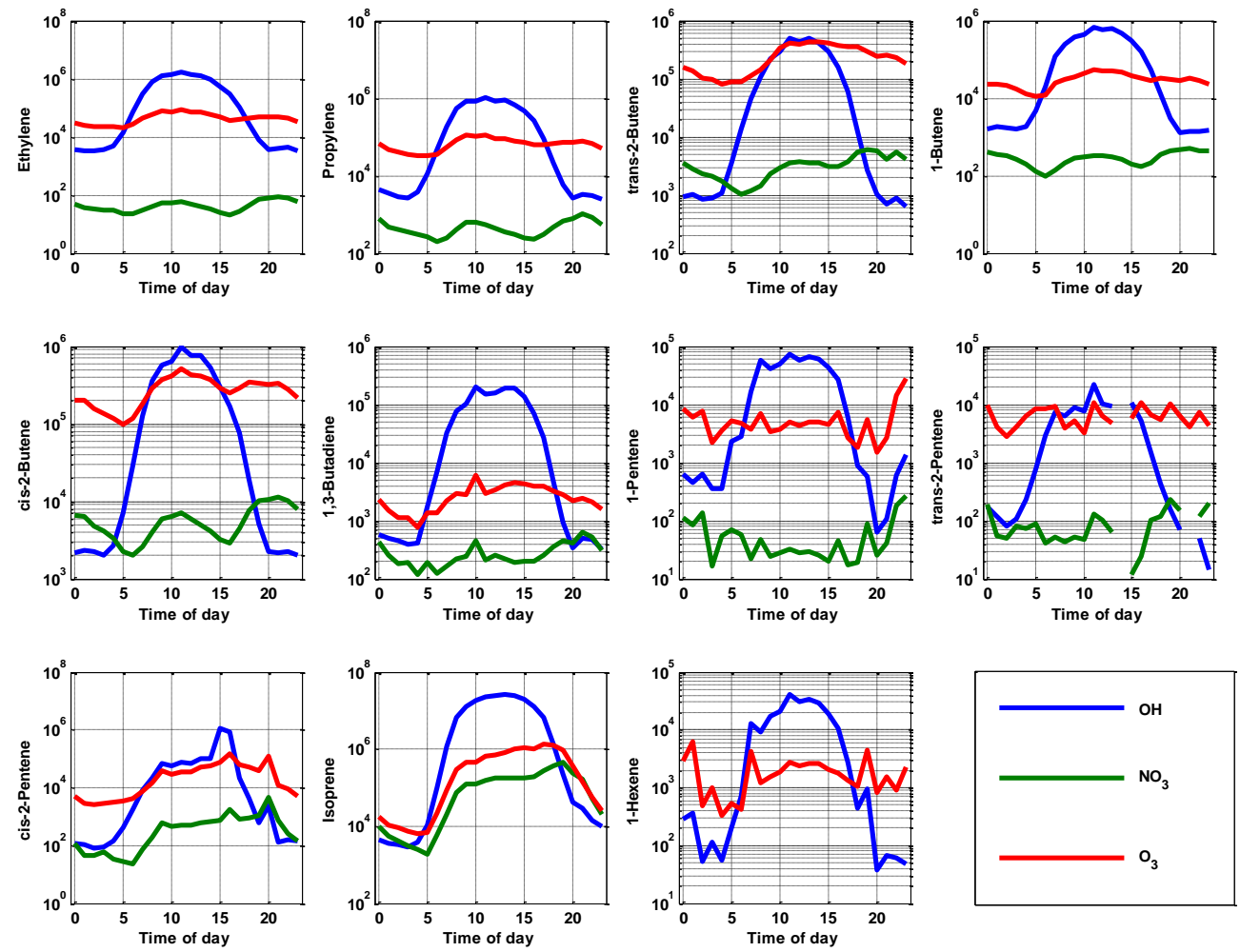

Figure S12. Diurnal variations of alkene species due to the reactions with $\mathrm{OH}$ radical (blue lines), $\mathrm{NO}_{3}$ radical (green lines) and $\mathrm{O}_{3}$ (red lines) (unit: molecules $\mathrm{cm}^{-3} \mathrm{~s}^{-1}$ ). 

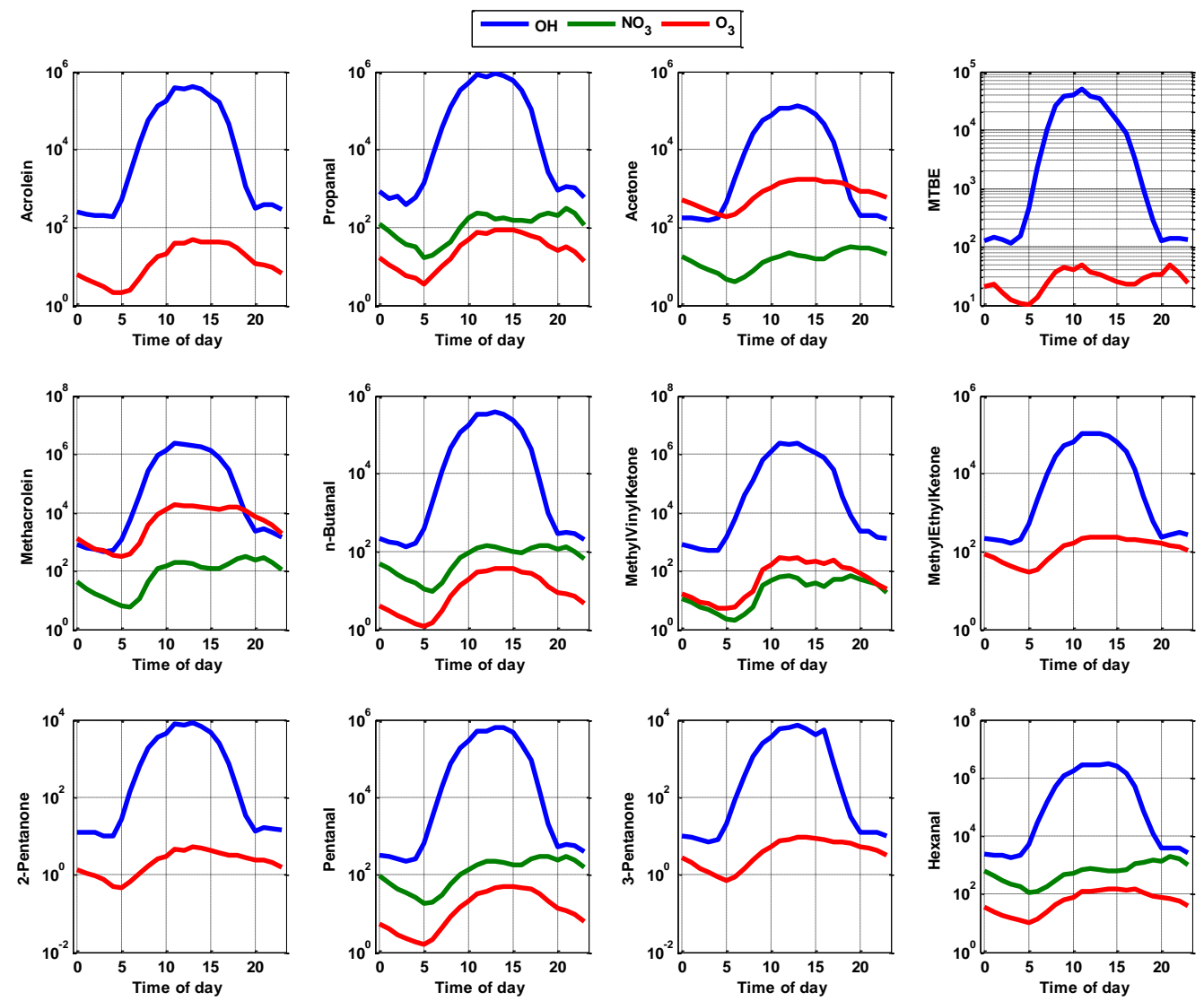

Figure S13. Diurnal variations of OVOC species due to the reactions with $\mathrm{OH}$ radical (blue lines), $\mathrm{NO}_{3}$ radical (green lines) and $\mathrm{O}_{3}$ (red lines) (unit: molecules $\mathrm{cm}^{-3} \mathrm{~s}^{-1}$ ). 

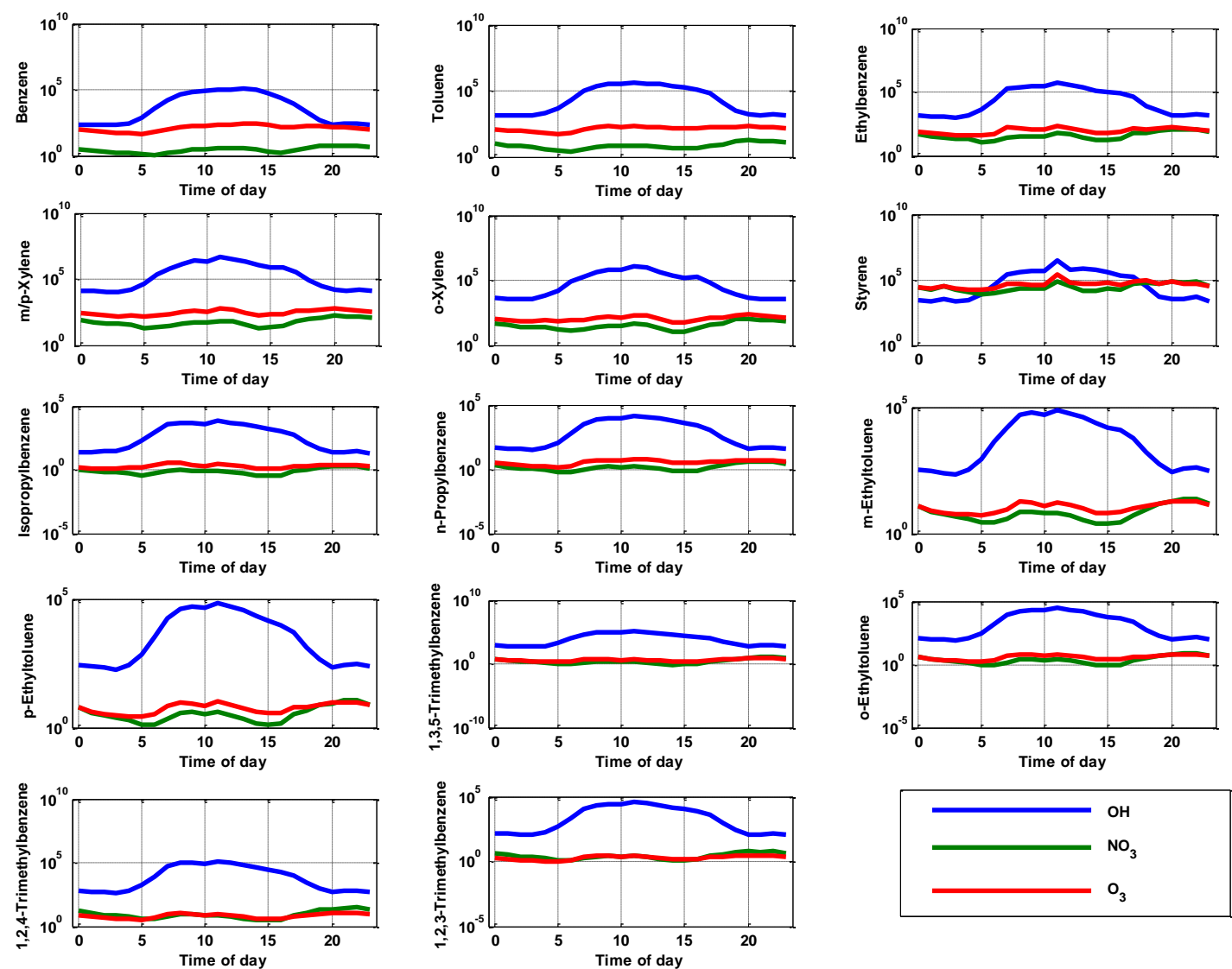

Figure S14. Diurnal variations of aromatic species due to the reactions with $\mathrm{OH}$ radical (blue lines), $\mathrm{NO}_{3}$ radical (green lines) and $\mathrm{O}_{3}$ (red lines) (unit: molecules $\mathrm{cm}^{-3} \mathrm{~s}^{-1}$ ). 


\section{Table captions}

Table S1. VOC species for the calculation of $R_{\mathrm{OH}_{1}}, R_{\mathrm{NO}_{3}}$ and $R_{O_{3}}$ in this study.

\begin{tabular}{|c|c|}
\hline $\begin{array}{l}\text { VOCs } \\
\text { groups }\end{array}$ & icluded \\
\hline Alkanes & $\begin{array}{l}\text { Ethane, propane, iso-butane, n-butane, cyclopentane, iso-pentane, n-pentane, } \\
\text { 2,2-dimethylbutane, 2,3-dimethylbutane, 2-methylpentane, 3-methylpentane, n-hexane, } \\
\text { 2,4-dimethylpentane, methylcyclopentane, 2-methylhexane, 2,3-dimethylpentane, cyclohexane, } \\
\text { 3-methylhexane, 2,2,4-trimethylpentane, n-heptane, methylcyclohexane, 2,3,4-trimethylpentane, } \\
\text { 2-methylheptane, 3-methylheptane, n-octane, nonane, n-decane, n-undecane }\end{array}$ \\
\hline Alkenes & $\begin{array}{l}\text { Ethylene, propylene, trans-2-butene, 1-butene, cis-2-butene, 1,3-butadiene, 1-pentene, } \\
\text { trans-2-pentene, cis-2-pentene, 1-hexene }\end{array}$ \\
\hline Aromatics & $\begin{array}{l}\text { Benzene, toluene, ethylbenzene, } \mathrm{m} / \mathrm{p} \text {-xylene, o-xylene, styrene, isopropylbenzene, } \\
\text { n-propylbenzene, m-ethyltoluene, p-ethyltoluene, o-ethyltoluene, 1,3,5-trimethylbenzene, } \\
\text { 1,2,4-trimethylbenzene, 1,2,3-trimethylbenzene. }\end{array}$ \\
\hline OVOCs & $\begin{array}{l}\text { Acrolein, propanal, acetone, MTBE, methacrolein, n-butanal, methylvinylketone, } \\
\text { methylethylketone, 2-pentanone, pentanal, 3-pentanone, hexanal }\end{array}$ \\
\hline Isoprene & Isoprene \\
\hline
\end{tabular}

